\title{
The role of nursing staff in the activities of daily living of nursing home residents
}

Citation for published version (APA):

den Ouden, M., Kuk, N. O., Zwakhalen, S. M. G., Bleijlevens, M. H. C., Meijers, J. M. M., \& Hamers, J. P. $\mathrm{H}$. (2017). The role of nursing staff in the activities of daily living of nursing home residents. Geriatric Nursing, 38(3), 225-230. https://doi.org/10.1016/j.gerinurse.2016.11.002

Document status and date:

Published: 01/01/2017

DOI:

10.1016/j.gerinurse.2016.11.002

Document Version:

Publisher's PDF, also known as Version of record

Document license:

Taverne

Please check the document version of this publication:

- A submitted manuscript is the version of the article upon submission and before peer-review. There can be important differences between the submitted version and the official published version of record.

People interested in the research are advised to contact the author for the final version of the publication, or visit the DOI to the publisher's website.

- The final author version and the galley proof are versions of the publication after peer review.

- The final published version features the final layout of the paper including the volume, issue and page numbers.

Link to publication

\footnotetext{
General rights Owners
rights.

- You may freely distribute the URL identifying the publication in the public portal. please follow below link for the End User Agreement:

www.umlib.nl/taverne-license

Take down policy

If you believe that this document breaches copyright please contact us at:

repository@maastrichtuniversity.nl

providing details and we will investigate your claim.
}

Copyright and moral rights for the publications made accessible in the public portal are retained by the authors and/or other copyright owners and it is a condition of accessing publications that users recognise and abide by the legal requirements associated with these

- Users may download and print one copy of any publication from the public portal for the purpose of private study or research.

- You may not further distribute the material or use it for any profit-making activity or commercial gain

If the publication is distributed under the terms of Article $25 \mathrm{fa}$ of the Dutch Copyright Act, indicated by the "Taverne" license above, 
Feature Article

\title{
The role of nursing staff in the activities of daily living of nursing home residents
}

\author{
Mirre den Ouden, MSc*, Nienke O. Kuk, MSc, Sandra M.G. Zwakhalen, RN PhD, \\ Michel H.C. Bleijlevens, PhD, Judith M.M. Meijers, RN, PhD, Jan P.H. Hamers, RN, PhD \\ Department of Health Services Research, CAPHRI School for Public Health and Primary Care, Maastricht University, Maastricht, The Netherlands
}

\section{A R T I C L E I N F O}

\section{Article history:}

Received 22 June 2016

Received in revised form

28 October 2016

Accepted 7 November 2016

Available online 7 December 2016

\section{Keywords:}

Activities of daily living

Nursing staff

Role

Nursing homes

Observation

Physical activity

Residents

Supervision

Support

Taking over

\begin{abstract}
A B S T R A C $T$
The aim of this cross-sectional study was to explore the role of nursing staff in residents' activities. Nursing home residents $(n=723$ ) were observed in their wards, randomly five times for one minute between 7 a.m. and 11 p.m. Resident's (in)activity and the role of nursing staff or others in this activity were recorded. Roles were defined as 'taking over the activity', 'giving support', or 'supervision'. Nurse observers were interviewed to obtain insight into their observation-experiences. Residents were observed in activities of daily living in $31 \%$ of all 3282 observations, and inactive in $57 \%$. Nursing staff provided support in 51\% of the observations and took over activities in 45\%; supervision was rarely observed (4\%). Nurse observers who knew the residents reported that a large part of activities were taken over unnecessarily. Based on these results, nursing staff are recommended to provide more supervision and support to optimize residents' activities and independence.
\end{abstract}

(C) 2016 Elsevier Inc. All rights reserved.

\section{Introduction}

Maintaining activities of daily living (ADL) and instrumental ADL (IADL) is of major importance in the frail nursing home population. It is well known that performing ADL and IADL, such as washing, dressing and preparing food, has a positive influence on physical functioning ${ }^{1}$ and is associated with a higher self-esteem ${ }^{2}$ and with a higher quality of life. ${ }^{3,4}$ Furthermore, residents' quality of life is positively influenced by their independence in these daily activities. ${ }^{5,6}$ Despite these positive effects, nursing home residents spend their day mainly inactive. ${ }^{7-9}$

Nursing homes are facilities that provide $24 \mathrm{~h}$ functional support and care for people who require assistance with daily activities, and have identified health needs. Nursing home care aims to provide a supportive, safe, and homelike environment in which residents are

\footnotetext{
Conflict of interest: None.

* Corresponding author. Maastricht University, Faculty of Health, Medicine and Life Sciences, CAPHRI School for Public Health and Primary Care, Department of Health Services Research, P.O. Box 616, 6200 MD Maastricht, The Netherlands. Fax: +31433884162 .

E-mail address: m.denouden@maastrichtuniversity.nl (M. den Ouden).
}

assisted to maintain their functional status as long as possible. ${ }^{10}$ In Dutch nursing homes, nursing staff are mainly certified nurse assistants (CNAs), ${ }^{11,12}$ with three years of secondary-vocational training. Besides, registered nurses (RNs), with four years of secondary-vocational training or bachelor-education, are part of the nursing staff. Henderson ${ }^{13}$ defined nursing in 1960 as: "The unique function of the nurse is to assist the individual, sick or well, in the performance of those activities contributing to health or its recovery that he would perform unaided if he had the necessary strength, will or knowledge. And to do this in such a way as to help him gain independence as rapidly as possible." This definition by Henderson $^{13}$ implies that, also in the nursing home, it is the core business of nursing staff to encourage residents to perform daily activities and to encourage their independence.

Since nursing staff provide $24 / 7$ care, they play a key role in care provision and, ideally, demonstrate leadership behavior in encouraging nursing home residents in daily activities and maintaining independence. Nursing home residents' dependence is related to nursing staff behavior. ${ }^{14}$ Nursing staff can play different roles in the activities of the residents, for example, nursing staff could give instructions to complete the activity step-by-step. Moreover, nursing staff could take over residents' activities, 
which is not encouraging independence and physical activity. Previous intervention studies ${ }^{2,15-24}$ have focused on changing the nursing behavior towards motivating and supportive behavior in the daily activities of nursing home residents. In these studies, nursing staff were taught motivational techniques to encourage residents. Most intervention studies reported on the effects on residents, for example, residents' functioning in ADL. Other studies $^{22-24}$ evaluated change in behavior of nursing assistants using observations. Nursing staff were observed for 15-30 min in these studies, and their performance of function-focused care activities was evaluated using the Restorative Care Behavior Checklist (RCBC). ${ }^{25}$ Function-focused care activities performed by nursing staff could be encouraging the resident verbally to walk or walk together with the resident by instead of pushing their wheelchair. Although these studies showed whether or not nursing assistants performed function focus care behaviors during care moments at an intervention setting, they do not provide insight into different roles of nursing staff in residents' activities during the day. Insight into the role of nursing staff in different activities of residents, especially ADL and IADL, could provide useful information for developing and evaluating nursing interventions to encourage residents in activities and their independence. Therefore, the aim of the current study was to explore the role of nursing staff in residents' ADL and IADL.

\section{Methods}

A cross-sectional mixed-method design was used in this study, consisting primarily of quantitative observations in Dutch nursing homes and additional qualitative semi-structured interviews. To explore the role of nursing staff in residents' ADL and IADL during daily nursing care, the observations were conducted anonymously. Due to the anonymous observations all residents and all nursing staff in the wards could be observed without participation bias. The observations were conducted in June and July of 2014. Dutch nursing homes provide long-term care in psychogeriatric and somatic wards. Psychogeriatric wards are provided for people with dementia, while somatic wards focus on people with physical problems. ${ }^{26}$ The qualitative component of this study consisted of semi-structured interviews with the nurse observers, these interviews were conducted after the quantitative data collection.

\section{Participants}

Seven nursing homes in the southern part of the Netherlands participated in this study. The participating nursing homes are embedded in the Living Lab of Aging and Long-Term Care. ${ }^{27}$ The nursing homes consisted of 19 psychogeriatric and 11 somatic longterm care wards and housed 723 residents (383 and 340 residents from psychogeriatric and somatic wards, respectively). The sample included the nursing home residents present in the ward during the observations, and the people who were involved in residents' activities, distinguishing between nursing staff (both RNs and CNAs) and others (such as family and volunteers). No distinction was made between CNAs and RNs, they were put together as "nursing staff." Furthermore, three of the five observers were RNs between 25 and 39 years of age, with up to 20 years of work experience.

\section{Measures}

The following background characteristics of the residents were extracted from the residents files: gender, age, mobility (mobile, wheelchair dependent or bedridden), functioning in ADL (measured by the Barthel index; $\mathrm{BI}$ ), ${ }^{28}$ and cognitive functioning (assessed by the Cognitive Performance Scale; CPS) ${ }^{29}$ The BI ranges from 0 to 20, with a lower score indicating increased disability, ${ }^{28}$ and the CPS ranges from 0 to 6 with a higher score indicating more severe cognitive impairment. ${ }^{29}$

A self-developed observation list was used to register the daily (in)activity the resident was engaged in, and the role of nursing staff and others in the resident's activity. The development of the observation list consisted of a pilot observation study, validity check, and adjustments to the list; more details about the development can be found elsewhere. ${ }^{7}$ The daily (in)activities residents could be engaged in were categorized into 1) inactivity, 2) ADL and IADL, and 3) communication and hobbies. When residents were engaged in daily activities, it did not mean that residents were physically active themselves, since their activities could be taken over.

ADL consisted of personal care (e.g., brushing teeth, combing one's hair), going to the bathroom, eating and drinking (e.g., eating with hands or cutlery), mobility (e.g., walking, pushing a wheelchair, changing position), dressing (e.g., taking off one's clothes), and bathing (e.g., having a shower, washing at the sink). IADL that can be relevant for nursing home residents in their wards included domestic activities (e.g., setting the table) and preparing food/pouring a drink (e.g., preparing a sandwich).

The role of nursing staff in residents' ADL and IADL was categorized as 'taking over the activity', 'giving support' or 'supervision.' 'Taking over the activity' was registered when nursing staff performed the activity instead of the resident (e.g., a resident in a wheelchair was pushed by the nurse, or a resident was dressed by a nurse). 'Giving support' consisted of verbal support (e.g., giving instructions), and/or physical support (e.g., taking somebody by the arm). 'Supervision' meant that the nurse observed the resident's activity and interfered when necessary (e.g., the nurse walked beside the resident and could intervene if the resident stumbled). These categories were based on a pilot observation study, in which residents' activities and positions, and the kind of support residents received (no support, some support or a lot of support) were scored.

Semi-structured interviews were conducted with each of the three nurse observers who performed the observations. The nurse observers were asked about their experiences during the observations, their perceptions of the role of nursing staff, and their ideas for positively changing the role of nursing staff in residents' daily activities.

\section{Procedure}

Permission for the anonymous observations was provided by the management of each participating nursing home by signing a research declaration. The contact person within the nursing home provided information about the number of residents in each ward. Nursing staff in the wards were informed about the observations and completed the inventory of the background characteristics of each resident living in the ward.

The observations were conducted by one out of five observers (three nurses, one research assistant, and one researcher). Two of nurse observers conducted the observations within the nursing home they were employed in. In order to prevent observation bias and to reach a high interrater reliability, all observers received a three and a half hours' training program before starting, in which they received instructions for observations, practiced observations using video fragments, and discussed the definitions 'taking over', 'support' and 'supervision' to reach consensus between the observers.

In each nursing home, the observations were performed during a $16 \mathrm{~h}$ period (between 7.00 a.m. and 11.00 p.m.), divided over two days. To provide an overview of the whole time period, the 
observations were divided into 5 time blocks. All wards within a nursing home were visited by an observer in a random sequence during each time block (randomization was carried out using http://www.randomizer.org). Theoretically, if all 723 residents were present in the wards during the five observation times, a total of 3615 observations could be conducted.

An observer walked around the ward and observed each resident present for one minute. The observer noted the main (in) activity the resident was engaged in during that minute. In addition, the role of nursing staff or others in the resident's activity was recorded, namely, who was involved (nursing staff or others) and, in the case of nursing staff, what their role was ('taking over the activity,' 'giving support' or 'supervision'). If an observation did not fit within the predefined categories, the observer could describe the observation in the "comment column.' The observer used a hand-held tablet, which was loaded with the observation list. The observation list was integrated into an Excel file and could be opened and adjusted during the observations using the e-Droid-cell Pro app. This file also provided information to the observer about the sequence of wards and observation times.

\section{Data analysis}

The data collected during the observations on the Excel files were transferred to SPSS (version 22, IBM, Armonk, NY). The residents' background characteristics were compared between the psychogeriatric and somatic wards using the chi-square test for the dichotomous variable (gender), and independent $t$-tests for the continuous variables (age, BI, and CPS). Descriptive analyses of the anonymous observations were conducted for all wards and the five observation times together. To obtain insights into the role of nursing staff, percentages of the different types of roles were calculated. Additionally, a chi-square test was conducted to compare the role of nursing staff in residents' ADL and IADL between the psychogeriatric and somatic wards. The interviews were recorded and transcribed afterward. The researcher summarized each interview and sent the summary to the nurse for a member check before analyzing the data.

To test the interrater reliability of the observers regarding their score of the role of nursing staff, an intraclass correlation coefficient (ICC) was calculated. ${ }^{30}$ Reliability was tested by the extent of agreement of a small sample of 85 observations (in 9 wards) between two observers during their observations in the nursing home. The role was scored as 1: taking over; 2: support; 3: supervision; and 4: no involvement. The ICC (two-way mixed absolute agreement) was 0.865 for the role of nursing staff, indicating good agreement between the raters. This ICC was high enough to decide to continue with the observations in the nursing home and not test the reliability any further.

\section{Ethical considerations}

The study protocol was approved by the Medical Research Ethics Committee. During all observations, the privacy of the residents was taken into account. For instance, the bathroom doors were not opened by the observer. All data, including background characteristics, were collected anonymously at ward level, which meant that residents could not be followed over time and that residents' characteristics could not be linked to the observations. Since the data were collected anonymously at ward level, the Medical Research Ethics Committee deemed exempt from individual consent of the nursing home residents. The three nurse observers signed an informed consent form for recording the interview.

\section{Results}

\section{Background characteristics of the residents}

Table 1 shows the background characteristics of the 723 nursing home residents living in the observed wards. In total, $68 \%$ of the residents were female. The nursing home residents living in psychogeriatric wards were, compared with the residents living in somatic wards, older, less severe dependent in ADL and more severe cognitive impaired. Furthermore, $61 \%$ of the residents in psychogeriatric ward were mobile, versus $27 \%$ of the residents in somatic wards. In total, $91 \%(n=3282)$ of the intended $(n=3615)$ observations were completed, the observation was not conducted if resident was not present in the ward. In the psychogeriatric wards, $93 \%$ of the intended observations were completed and $89 \%$ in the somatic wards. The maximum number of observed residents in each ward during the different observation moments showed that at least 717 of the 723 individual residents were observed.

\section{Overall involvement in daily activities}

Nursing home residents were engaged in ADL and IADL during $31 \%$ ( $n=1005$ ) of all observations, and residents were observed as inactive during $57 \%$ of all observations. The flowchart in Fig. 1 provides an overview of the observed (in)activities with and without involvement of nursing staff and others. The flowchart also shows the involvement of nursing staff and others in the residents' ADL and IADL, and the role of nursing staff. A small number of involvement observations ( $n=31,1 \%$ ) was missing, they were not recorded on the tablet by the observer.

In $11 \%$ of all observations, the involvement of nursing staff or others in the residents' daily activities was noted. Activities in which involvement was noted were mainly ADL and IADL (78\%). When no involvement was recorded, residents were generally observed as inactive (65\%) (see Fig. 1). Nursing staff ( $n=235$ observations) were four times more often involved in residents' ADL and IADL than others, such as family and volunteers ( $n=52$ observations). Table 2 shows the observed involvement, which varied between the different ADL and IADL. Eating and drinking, and mobility, were most often observed without the involvement of nursing staff or others, respectively $76 \%(n=209)$ and $78 \%$ $(n=374)$. Bathing, dressing, and going to the bathroom were most often observed with the involvement of nursing staff or others, respectively $88 \%(n=35), 69 \%(n=20)$, and $51 \%(n=23)$.

\section{The role of nursing staff in residents' $A D L$ and IADL}

When nursing staff were involved, they provided physical and/or verbal support in $51 \%(n=119)$ of the observations, took over residents' activities in $45 \%(n=106)$, and provided supervision

Table 1

Background characteristics of nursing home residents living in psychogeriatric and somatic wards.

\begin{tabular}{lllll}
\hline & $\begin{array}{l}\text { Total } \\
{[N=723]}\end{array}$ & $\begin{array}{l}\text { Psychogeriatric } \\
{[n=383]}\end{array}$ & $\begin{array}{l}\text { Somatic } \\
{[n=340]}\end{array}$ & $p$ value \\
\hline Age, mean (SD) & $83.0(8.9)$ & $85.2(6.4)$ & $80.5(10.6)$ & $<0.001^{*}$ \\
BI, mean (SD) & $7.6(5.8)$ & $8.0(6.2)$ & $7.1(5.3)$ & $<0.001^{*}$ \\
BI $\leq 9 n(\%)$ & $455(63)$ & $224(58)$ & $231(68)$ & $0.007^{*}$ \\
CPS, mean (SD) & $2.6(1.9)$ & $3.5(1.7)$ & $1.7(1.7)$ & $<0.001^{*}$ \\
\hline
\end{tabular}

*Significant difference $(p<0.05)$ between residents living in psychogeriatric and somatic wards.

a BI; Barthel index, range BI: 0-20 (a lower score indicates increased disability, where a score $\leq 9$ means severe need of help). ${ }^{28}$

b CPS; cognitive performance scale, range CPS: 0-6 (a higher score indicates more severe cognitive impairment). ${ }^{29}$ 


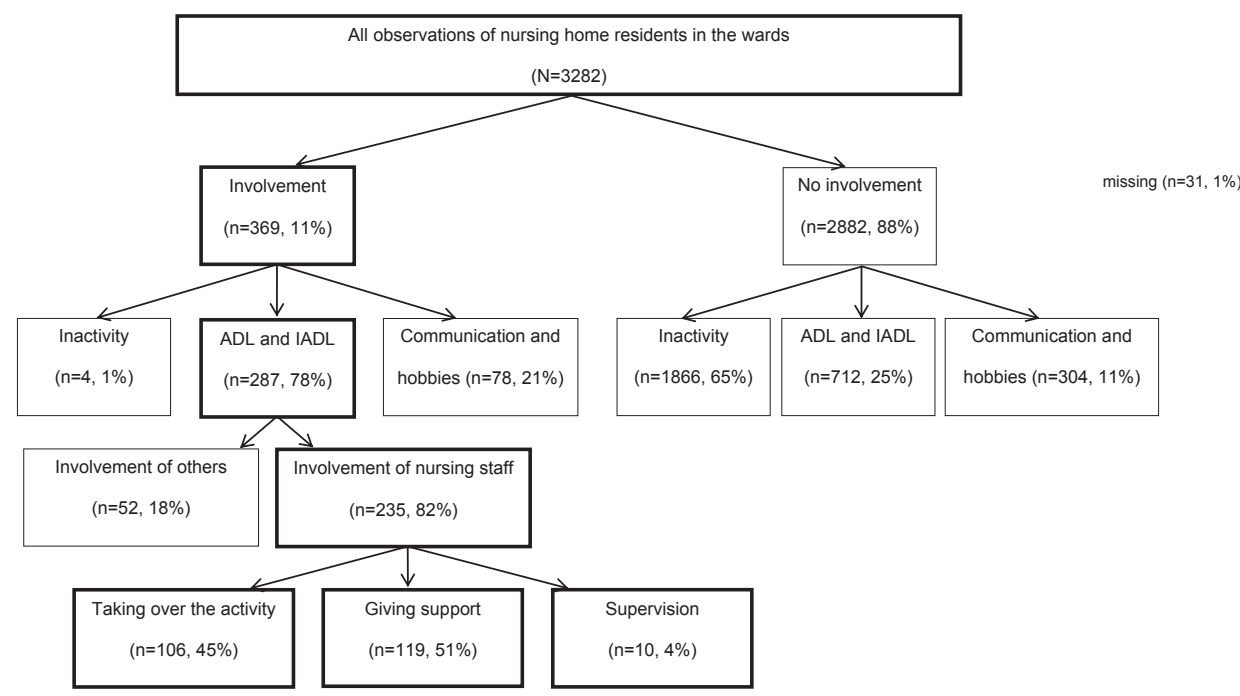

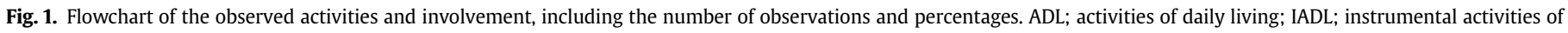
daily living.

in $4 \%(n=10)$. The nursing staff's role differed per activity (see Table 2); they commonly took over activities involving preparing food/pouring a drink $(83 \%, n=5)$, personal care $(61 \%, n=17)$, and bathing ( $50 \%, n=17$ ), and provided physical and/or verbal support mostly when residents were going to the bathroom $74 \%(n=17)$. Supervision of ADL and IADL was seldom observed. There were no statistically significant differences in the role of nursing staff in residents' ADL and IADL between the psychogeriatric $(n=105)$ and somatic wards $(n=130)$. 'Taking over' was scored in $51 \%$ of the observations in the somatic wards and in $40 \%$ of the observations in the psychogeriatric wards $(p=0.080)$. Nursing staff provided 'support' in $44 \%$ of the observations in the somatic wards, compared with $56 \%$ in the psychogeriatric wards $(p=0.060)$. 'Supervision' was observed in $5 \%$ of all observations in the somatic wards and in $4 \%$ of the observations in the psychogeriatric wards $(p=0.730)$.

\section{Experience of the nurse observers}

The nurse observers $(n=3)$, acknowledged the large amount of inactivity of nursing home residents. Further, the nurse observers

Table 2

Observed involvement and the different roles of nursing staff in residents' ADL and IADL.

\begin{tabular}{|c|c|c|c|c|}
\hline $\begin{array}{l}\text { No } \\
\text { involvement }\end{array}$ & $\begin{array}{l}\text { Involvement } \\
\text { of others }\end{array}$ & $\begin{array}{l}\text { Involvemen } \\
\text { nursing sta }\end{array}$ & $\begin{array}{l}t \text { and role } \\
\text { f }[n=23\end{array}$ & $\begin{array}{l}\text { es of } \\
5]\end{array}$ \\
\hline$n$ & $n$ & $n \begin{array}{ll}\text { Taking } \\
& \text { over } \\
& n(\%)\end{array}$ & $\begin{array}{l}\text { Support } \\
n(\%)\end{array}$ & $\begin{array}{l}\text { Supervision } \\
n(\%)\end{array}$ \\
\hline
\end{tabular}

\begin{tabular}{|c|c|c|c|c|c|c|}
\hline \multicolumn{7}{|l|}{ ADL } \\
\hline Personal care & 51 & 4 & 28 & $17(61)$ & $11(39)$ & $0(0)$ \\
\hline $\begin{array}{l}\text { Going to the } \\
\text { bathroom }\end{array}$ & 22 & 0 & 23 & $5(22)$ & $17(74)$ & $1(4)$ \\
\hline $\begin{array}{l}\text { Eating and } \\
\text { drinking }\end{array}$ & 209 & 12 & 54 & $25(46)$ & $28(52)$ & $1(2)$ \\
\hline Mobility & 374 & 32 & 71 & $29(41)$ & 35 (49) & $7(10)$ \\
\hline Dressing & 9 & 1 & 19 & $8(42)$ & $11(58)$ & $0(0)$ \\
\hline Bathing & 5 & 1 & 34 & $17(50)$ & $16(47)$ & $1(3)$ \\
\hline \multicolumn{7}{|l|}{ IADL } \\
\hline $\begin{array}{l}\text { Domestic } \\
\text { activities }\end{array}$ & 27 & 0 & 0 & - & - & - \\
\hline $\begin{array}{l}\text { Preparing } \\
\text { food }\end{array}$ & 15 & 2 & 6 & $5(83)$ & $1(17)$ & $0(0)$ \\
\hline
\end{tabular}

ADL; activities of daily living, IADL; instrumental activities of daily living. who knew the residents mentioned that a large part of residents' activities were unnecessarily taken over by the nursing staff: residents could have performed the activities themselves (with support or supervision). Reasons for nursing staff to take over activities included time pressure, expectations, and lack of knowledge. The nurse observers found it most remarkable that the observations made them aware of the large amount of inactivity of among the nursing home residents and the amount of activities that were taken over by nursing staff. The nurses stated that, given the findings, a change is necessary, however, it will be hard and take time to change nursing staff behavior. Their ideas for improvement were obtaining insight into residents' capacity and preferences, making appointments, pronouncing expectations, and being aware of their own behavior.

\section{Discussion}

The aim of this study was to explore the role of nursing staff in residents' ADL and IADL. When nursing staff were involved in residents' ADL or IADL, they provided verbal and/or physical support in $51 \%$ of the observations; in $45 \%$ they completely took over the residents' activities. Supervision was rarely observed (4\%). The observations created awareness among the nurse observers about the large amount of inactivity of nursing home residents and a large part of ADL and IADL were unnecessarily taken over by nursing staff.

Involvement of nursing staff and others was mainly observed in residents' ADL and IADL, which was to be expected, since nursing home residents show a dependency in their functioning. Eating and drinking, and mobility, were frequently performed without involvement of nursing staff or others, whereas bathing was most often observed with involvement. This is in line with the hierarchical order of ADL decline; first, older people lose their ability to bathe independently, thereafter, they lose their independence in mobility, and at the last, older people lose their ability to eat independently. ${ }^{31,32}$

Nursing staff have a major role in increasing the activity levels of nursing home residents; however, this might be challenging. Nursing home care is a high demanding nursing practice area and the availability of nursing staff is limited. A Dutch report about staffing and quality of care indicates that, in nursing home wards of 30 residents, on average four direct care members are available, and 
about 1.5 staff members to support the nursing staff. ${ }^{33}$ Geriatric nurses are trained to perform in a complex care environment so that nursing home residents remain as independent as possible in this institutionalized long-term care setting. Without any doubt this complexity requires nursing staff awareness of the possibilities and possible complications in the process of encouraging activities. Nursing staff have various tasks, such as direct and indirect care, practical nursing tasks, support, logistics, administration and communication. $^{34,35}$ They need to switch rapidly between these $\operatorname{tasks}^{36}$; and multi-tasking is part of the job. ${ }^{34}$ Nursing staff may experience a high workload ${ }^{21,37}$; consequently, they may feel that they do not have time to talk or listen to the residents. ${ }^{36}$ This perceived shortage of time and focus on their tasks could have led to more activities being taken over by nursing staff in the current study, instead of providing supervision or support. Nursing staff are mainly focused on the tasks they need to do (task-oriented) instead of focusing on the residents' needs and preferences (personcentered). ${ }^{38}$ Nurses should ensure that residents receive optimal care based on the person's abilities and nursing care needs. Therefore, nursing models that emphasize individualized personcentered care should be embraced. By applying such an individualized care approach; nursing staff create a stimulating living environment.

When reflecting upon the observations with the nurse observers, they pointed out that the observations made them aware of the large amount of inactivity, and that many activities that were taken over by nursing staff could have been performed by the residents themselves. This awareness seems to be essential in the process of behavioral change. ${ }^{39}$ An observational approach to become aware of the magnitude of the problem and the explicit role of the nurses may be an important aspect to achieve a change in the nursing staff behavior that can be included in intervention and training programs.

Encouraging residents to engage in daily activities is challenging, but essential since residents may show decreased initiation of activities. ${ }^{40}$ If nursing staff do not encourage residents in daily activities but take over these activities instead, the residents will become more care dependent. ${ }^{41}$ For example, losing mobility is associated with different care problems, such as incontinence and pressure ulcers. ${ }^{42}$ In addition, encouraging residents' mobility is necessary since it gives residents a sense of freedom, choice and independence, and is therefore a key factor in their quality of life. ${ }^{43}$

Nursing staff provide care in the residents' direct environment and have the most contact with them; therefore, it is expected that they should encourage nursing home residents to carry out daily activities. Based on the results of this study, nursing staff are advised to change their behavior to encourage residents to become engaged in more activities, and to provide more supervision or support instead of taking over residents' activities, in order to increase activity levels and to maintain the residents' capacity and independence.

Despite the differences in cognitive and physical status between residents in psychogeriatric and somatic wards, the large amount of residents' inactivity and the role of nursing staff in these wards are comparable. Therefore, in both wards interventions should be aimed at encouraging residents' daily activities and independence. However, the differences in residents' cognitive and physical status implicates that nursing staff should use a different approach in encouraging residents. ${ }^{44}$ Residents in psychogeriatric wards commonly have cognitive problems, and therefore might need demonstration of a certain activity with step-by-step support. Residents living in somatic wards suffer from physical impairments, they often understand explanations, and therefore, might need more physical support, general instructions and feedback during daily activities.
Nursing staff could decrease the large amount of inactivity by offering relevant activities during the day, tailored to residents' capacity and preferences. ${ }^{4}$ To encourage nursing home residents it is important to avoid highly demanding activities and build a trusting relationship. ${ }^{45}$ Nursing staff should discuss activity preferences with the resident (and family) and could collaborate with the nursing home physician and the multidisciplinary team, including physiotherapists, occupational therapists, and recreational therapists. This encouragement of activities and independence, based on residents' capacity and preference, fits into the cultural change that is ongoing from the medical model towards resident-directed care. ${ }^{46}$ Traditional nursing home wards shift to small scale wards with a homelike environment, for example in Green House homes. ${ }^{47}$ Nursing home residents living in these wards could be engaged in IADL activities, such as preparing food or setting the table.

To change nursing behavior, nursing staff need education on how to encourage residents in daily activities. ${ }^{2,15-24}$ Other important components of existing intervention studies that aim to change nursing behavior, such as function-focused care, ${ }^{19-24}$ are policy and coaching. Nursing staff should be supported by their management in the encouragement of activities and independence of nursing home residents. The management should underline the importance of activities and independence of resident and could facilitate training and coaching for nursing staff in the encouragement of residents.

\section{Limitations}

Some limitations of this study need to be addressed. Because of the anonymous observations, it is unknown which particular resident and nursing staff were observed; therefore, the resident's characteristics could not be linked with the role of nursing staff. It is not known if the nursing staff were more often involved and had different roles in the activities of residents with a lower functional capacity, that is, residents who needed more support by the nursing staff. Furthermore, the characteristics of the involved nursing staff (and others) were not assessed. Hence, it is not possible to examine whether the characteristics of the nursing staff, for example, educational level or years of experience, were associated with the extent to which activities were taken over. Lastly, when residents were observed without the involvement of nursing staff or others, it remains unclear if there had been involvement before the observation. The residents possibly had been encouraged to perform that activity themselves, and as a consequence, no involvement was observed.

\section{Conclusions}

This study shows that, when involved, nursing staff took over almost half of residents' ADL and IADL. Supervision of these activities, in which the nurse observed a resident and could interfere when necessary, was rarely observed. Nurses who conducted the observations reported that many activities were unnecessarily taken over; residents could have performed these themselves. It becomes imperative that nurses have to demonstrate competencies in understanding the residents' needs and how to meet these care needs. This starts at nursing home admission from initial assessment through the evaluation of care that is planned. Encouraging residents' daily activities and their independence in these activities should be a key role of nursing staff in order to decrease residents' inactivity and functional decline. Future studies should provide tools to help nursing staff to encourage residents' activities, and their independence in daily care. 


\section{Acknowledgements}

The authors would like to thank the participating long-term care organizations (Cicero Zorggroep, Envida, MeanderGroep ZuidLimburg, Mosae Zorggroep, Zuyderland, Sevagram and Vivantes) and the observers for their support in collecting the data.

Funding: This work was funded by The Netherlands Organization for Health Research and Development (ZonMw 520001003), The Hague, The Netherlands.

\section{References}

1. Gronstedt H, Frandin K, Bergland A, et al. Effects of individually tailored physical and daily activities in nursing home residents on activities of daily living, physical performance and physical activity level: a randomized controlled trial. Gerontology. 2013;59:220-229.

2. Blair CE. Effect of self-care ADLs on self-esteem of intact nursing home residents. Issues Ment Health Nurs. 1999;20:559-570.

3. Edvardsson D, Petersson L, Sjogren K, Lindkvist M, Sandman PO. Everyday activities for people with dementia in residential aged care: associations with person-centredness and quality of life. Int J Older People Nurs. 2014;9:269-276.

4. Smit D, de Lange J, Willemse B, Twisk J, Pot AM. Activity involvement and quality of life of people at different stages of dementia in long term care facilities. Aging Ment Health; 2015;1-10.

5. Chan C, Slaughter S, Jones C, Wagg A. Greater independence in activities of daily living is associated with higher health-related quality of life scores in nursing home residents with dementia. Healthcare. 2015;3:503-518.

6. Andersen CK, Wittrup-Jensen KU, Lolk A, Andersen K, Kragh-Sorensen P. Ability to perform activities of daily living is the main factor affecting quality of life in patients with dementia. Health Qual Life Out. 2004;2:52.

7. den Ouden M, Bleijlevens MHC, Meijers JMM, et al. Daily (in)activities of nursing home residents in their wards: an observation study. J Am Med Dir Assoc. 2015;16:963-968.

8. MacRae PG, Schnelle JF, Simmons SF, Ouslander JG. Physical activity levels of ambulatory nursing home residents. J Aging Phys Act. 1996;4:264-278.

9. Harper Ice G. Daily life in a nursing home: has it changed in 25 years? J Aging Stud. 2002;16:345-359.

10. Sanford AM, Orrell M, Tolson D, et al. An international definition for "nursing home". J Am Med Dir Assoc. 2015;16:181-184.

11. Verkaik R, Francke AL, van Meijel B, Spreeuwenberg PMM, Ribbe MW, Bensing JM. The introduction of a nursing guideline on depression at psychogeriatric nursing home wards: effects on certified nurse assistants. Int J Nurs Stud. 2011;48:710-719.

12. Backhaus R, van Rossum E, Verbeek H, et al. Quantity of staff and quality of care in Dutch nursing homes: a cross-sectional study. J Nurs Home Res. 2016;2:90-93.

13. Henderson V. Basic Principles of Nursing Care. Geneva: International Council of Nurses; 1960.

14. Barton EM, Baltes MM, Orzech MJ. Etiology of dependence in older nursing home residents during morning care: the role of staff behavior. J Pers Soc Psychol. 1980;38:423-431.

15. Morris JN, Fiatarone M, Kiely DK, et al. Nursing rehabilitation and exercise strategies in the nursing home. J Gerontol A Biol Sci Med Sci. 1999;54:494-500.

16. Johnson CSJ, Meyers AM, Jones GR, et al. Evaluation of the restorative care education and training program for nursing homes. Can J Aging. 2005;24:115-126.

17. Blair CE. Combining behavior management and mutual goal setting to reduce physical dependency in nursing home residents. Nurse Res. 1995;44:160-165.

18. Blair CE, Glaister J, Brown A, Phillips C. Fostering activities of daily living by intact nursing home residents. Educ Gerontol. 2007;33:679-699.

19. Galik EM, Resnick B, Gruber-Baldini A, et al. Pilot testing of the restorative care intervention for the cognitively impaired. J Am Med Dir Assoc. 2008:9:516-522.

20. Resnick B, Gruber-Baldini AL, Zimmerman S, et al. Nursing home resident outcomes from the Res-Care intervention. J Am Geriatr Soc. 2009;57:1156-1165.

21. Resnick B, Simpson M, Bercovitz A, et al. Pilot testing of the restorative care intervention: impact on residents. J Gerontol Nurs. 2006;32:39-47.

22. Resnick B, Simpson M, Bercovitz A, et al. Testing of the res-care pilot intervention: impact on nursing assistants. Geriatr Nurs. 2004;25:292-297.
23. Resnick B, Gruber-Baldini AL, Galik E, et al. Changing the philosophy of care in long-term care: testing of the restorative care intervention. Gerontologist. 2009;49:175-184.

24. Galik E, Resnick B, Hammersla M, Brightwater J. Optimizing function and physical activity among nursing home residents with dementia: testing the impact of function-focused care. Gerontologist. 2014;54:930-943.

25. Resnick B, Rogers V, Galik E, Gruber-Baldini AL. Measuring restorative care provided by nursing assistants: reliability and validity of the restorative care behavior checklist. Nurs Res. 2007;56:387-398.

26. Schols JM, Crebolder HF, van Weel C. Nursing home and nursing home physician: the Dutch experience. J Am Med Dir Assoc. 2004;5:207-212.

27. Verbeek H, Zwakhalen SMG, Schols JMGA, Hamers JPH. Keys to successfully embedding scientific research in nursing homes: a win-win perspective. J Am Med Dir Assoc. 2013;14:855-857.

28. de Haan R, Limburg M, Schuling J, Broeshart J, Jonkers L, van Zuylen P. Clinimetric evaluation of the Barthel index, a measure of limitations in dailly activities [in Dutch]. Ned Tijdschr Geneeskd. 1993;137:917-921.

29. Morris JN, Fries BE, Mehr DR, et al. MDS cognitive performance scale. J Gerontol. 1994;49:M174-M182.

30. Shrout PE, Fleiss JL. Intraclass correlations: uses in assessing rater reliability. Psychol Bull. 1979;86:420-428.

31. Katz S, Ford A, Moskowitz R, Jackson B, Jaffe M. Studies of illness in the aged. The index of ADL: a standardized measure of biological and psychosocial function. JAMA. 1963;185:914-919.

32. Walk D, Fleishman R, Mandelson J. Functional improvement of elderly residents of institutions. Gerontologist. 1999;39:720-728.

33. Hingstman TL, Langelaan M, Wagner C. De dagelijkse bezetting en kwaliteit van zorg in instellingen voor langdurige zorg; 2012;73-79. Available from: http:// www.nivel.nl/sites/default/files/bestanden/Rapport-dagelijkse-bezetting-zorgin-instellingen.pdf; Accessed 21 June 2016.

34. Munyisia EN, Yu P, Hailey D. How nursing staff spend their time on activities in a nursing home: an observational study. J Adv Nurs. 2011;67:1908-1917.

35. Paquay L, De Lepeleire J, Milisen K, Ylieff M, Fontaine O, Buntinx F. Tasks performance by registered nurses and care assistants in nursing homes: a quantitative comparison of survey data. Int J Nurs Stud. 2007;44:1459-1467.

36. Mallidou AA, Cummings GG, Schalm C, Estabrooks CA. Health care aides use of time in a residential long-term care unit: a time and motion study. Int J Nurs Stud. 2013:50:1229-1239.

37. Kieft RA, de Brouwer BB, Francke AL, Delnoij DM. How nurses and their work environment affect patient experiences of the quality of care: a qualitative study. BMC Health Serv Res. 2014;14:249.

38. Tuinman A, de Greef MH, Krijnen WP, Nieweg RM, Roodbol PF. Examining time use of Dutch nursing staff in long-term institutional care: a time-motion study. J Am Med Dir Assoc. 2016;17:148-154.

39. Elwyn G, Marrin K, Frosch D, White J. Sustainable change sequence: a framework for developing behavior change interventions for patients with longterm conditions. Eur J Pers Cent Healthc. 2014;2:212-216.

40. Cook C, Fay S, Rockwood K. Decreased initiation of usual activities in people with mild-to-moderate Alzheimer's disease: a descriptive analysis from the VISTA clinical trial. Int Psychogeriatr. 2008;20:952-963.

41. Schüssler S, Dassen T, Lohrmann C. Care dependency and nursing care problems in nursing home residents with and without dementia: a cross-sectional study. Aging Clin Exp Res. 2014;28(5):973-982.

42. Lahmann NA, Tannen A, Kuntz S, et al. Mobility is the key! Trends and associations of common care problems in German long-term care facilities from 2008 to 2012. Int J Nurs Stud. 2015;52:167-174.

43. Bourret EM, Bernick LG, Cott CA, Kontos PC. The meaning of mobility for residents and staff in long-term care facilities. J Adv Nurs. 2002;37:338345.

44. Braun SM, Kleynen M, Bleijlevens MHC, et al. "Interactive surfaces" technology as a potential tool to stimulate physical activity in psychogeriatric nursing home residents. Disabil Rehabil Assist Technol. 2015;10:486-492.

45. van Alphen HJ, Hortobagyi T, van Heuvelen MJ. Barriers, motivators, and facilitators of physical activity in dementia patients: a systematic review. Arch Gerontol Geriatr. 2016;66:109-118.

46. White-Chu EF, Graves WJ, Godfrey SM, Bonner A, Sloane P. Beyond the medical model: the culture change revolution in long-term care. J Am Med Dir Assoc. 2009; $10: 370-378$

47. Sloane PD, Zimmerman S, D'Souza MF. What will long-term care be like in 2040? N C Med J. 2014;75:326-330. 